\title{
Photosynthetic impact of hypoxia on in hospite zooxanthellae in the scleractinian coral Pocillopora damicornis
}

\author{
Karin E. Ulstrup, Ross Hill, Peter J. Ralph* \\ Institute for Water and Environmental Resource Management, Department of Environmental Sciences, \\ University of Technology, Sydney, Westbourne St. Gore Hill, New South Wales 2065, Australia
}

\begin{abstract}
Shallow water coral reefs may experience hypoxia under conditions of calm weather doldrums. Anaerobic responses of endosymbionts (i.e. zooxanthellae) within Pocillopora damicornis coral colonies were tested using both slow and fast chlorophyll a fluorescence induction kinetics. Zooxanthellae were examined in hospite when exposed to control conditions $\left(26^{\circ} \mathrm{C}, 200 \mu \mathrm{mol}\right.$ photons $\mathrm{m}^{-2} \mathrm{~s}^{-1}, 100 \%$ air-saturation, $4 \mathrm{~cm} \mathrm{~s}^{-1}$ flow) and to 2 treatments of reduced air content (40 and $0 \%$, achieved by controlling the $\mathrm{N}_{2}: \mathrm{O}_{2}$ ratio in water circulating at $2 \mathrm{~cm} \mathrm{~s}^{-1}$. Furthermore, the impact of water flow on photosynthesis was examined at $0 \%$ air saturation by turning off the flow entirely $\left(0 \mathrm{~cm} \mathrm{~s}^{-1}\right)$, thereby mimicking the environmental conditions of calm weather doldrums. Corals exposed to depleted air content $(0 \%$ with and without flow) showed a significant decrease $(p<0.001)$ in effective quantum yield $\left(\phi_{\text {PSII }}\right)$ in comparison with controls. Maximum quantum yield was significantly reduced when gas exchange was inhibited ( $0 \%$ without flow), whereas non-photochemical quenching (NPQ) was not affected. Fast polyphasic fluorescence transients of chlorophyll a fluorescence showed a significant increase in minimum dark-adapted fluorescence, $F_{0}$, when corals were exposed to anaerobic conditions. Furthermore, an increase in the J peak (2 ms) corresponding to the reduction of the primary electron acceptor, $Q_{A}$, was observed in $0 \%$ air-saturation with flow. We found that the most sensitive parameters for detecting physiological change associated with hypoxia were $\phi_{\text {PSII }}$ using slow (pulse-amplitude modulation) fluorescence kinetics, as well as an increase in the $\mathrm{O}$ peak, $\varphi_{\mathrm{Po}}$ (electron transport efficiency before $\mathrm{Q}_{\mathrm{A}}$ ), and an elevation of the $\mathrm{J}$ peak on a doublenormalised transient using fast (Plant Efficiency Analyser) induction kinetics.
\end{abstract}

KEY WORDS: Fluorescence · Fast-induction kinetics $\cdot$ Pulse-amplitude modulation · Photosystem II · PSII

\section{INTRODUCTION}

The effect of hypoxia (defined as the absence of air or free oxygen) on Photosystem II (PSII) in photosynthesising aquatic organisms is largely unexplored (Schreiber \& Vidaver 1974, Kühl et al. 1995, Schreiber et al. 2002). This is paradoxical, especially in corals, considering the frequent and sometimes prolonged periods of calm weather often encountered in shallow water environments such as reef flats and lagoons (e.g. Lesser et al. 1994, Nakamura \& van Woesik 2001, Nakamura et al. 2003). In situ flow conditions mea- sured in the reef environment range between 1 and $39 \mathrm{~cm} \mathrm{~s}^{-1}$ (Dennison \& Barnes 1988, Patterson et al. 1991). An increase in the thickness of the diffusive boundary layer (DBL) is linked to a reduction in water flow across an organism's surface (e.g. Patterson et al. 1991, Kühl et al. 1995) leading to reduced gasexchange, which can induce anaerobiosis (Schreiber \& Vidaver 1974, Kühl et al. 1995). Anaerobiosis is the physiological condition induced by hypoxic water. Coral-algae symbioses are complex systems where both components are inter-related and are mutually affected by abiotic factors, such as dissolved gas con- 
tent which fluctuates with flow (Dennison \& Barnes 1988, Kühl et al. 1995, Nakamura \& van Woesik 2001, Brown et al. 2002, Nakamura et al. 2003). Thus, water motion has been found to increase both the respiration of the host and photosynthesis of the algae known as zooxanthellae (Symbiodinium spp.) (Patterson et al. 1991). Coral colonies are more prone to bleaching (whitening of corals due to loss of either symbiotic algae or their pigment, or both) when enduring lowflow conditions (Nakamura \& van Woesik 2001, Nakamura et al. 2003). Under such conditions, zooxanthellae may become photo-inhibited due to a build-up of harmful oxygen free radicals (Nakamura \& van Woesik 2001), which target the D1 protein in PSII reaction centres.

The effect of hypoxic conditions on photo-physiological performance has been addressed on numerous occasions with terrestrial plants using PAM (pulseamplitude modulation) fluorescence techniques (e.g. Schreiber \& Vidaver 1974) and, to a lesser extent, fastinduction kinetics (e.g. Kirilovsky \& Etienne 1991, Haldimann \& Strasser 1999). Reported physiological impacts on PSII under hypoxic conditions include the formation of reductants due to the onset of chlororespiration (Garab et al. 1989, Miyake et al. 1994). Under anaerobic conditions, the plastoquinone (PQ) pool becomes reduced in the dark, which leads to the reduction of the primary electron acceptor of PSII, $\mathrm{Q}_{\mathrm{A}}$ (Schreiber \& Vidaver 1974, 1975). This ultimately results in a decline in the photochemical efficiency of PSII $\left(F_{\mathrm{v}} / F_{\mathrm{m}}=\left[F_{\mathrm{m}}-F_{0}\right] / F_{\mathrm{m}}\right.$, where $F_{\mathrm{v}}$ is variable fluorescence, $F_{\mathrm{v}} / F_{\mathrm{m}}$ is maximum quantum yield, and $F_{\mathrm{m}}$ and $F_{0}$ are maximum and minimum dark-adapted fluorescence, respectively), as a large proportion of the electron transport chain is pre-reduced, thus increasing the number of closed PSII reaction centres; this reduces $F_{\mathrm{m}}$. Effects such as increased $F_{0}$ and a rise in the amplitude of the J peak (see 'Materials and methods') along a fast-induction curve have also been reported (Kirilovsky \& Etienne 1991, Haldimann \& Strasser 1999).

In corals, PAM fluorometry has been mainly used to address stress responses in connection with bleaching, by examining the PSII maximum and effective quantum yields of zooxanthellae as proxies of health (e.g. Jones et al. 2000, Jones \& Hoegh-Guldberg 2001, Ralph et al. 2001) and using non-photochemical quenching (NPQ) as an indicator of dissipation of excess energy (Warner et al. 1996, Jones et al. 1998). Fast-induction kinetics using the Plant Efficiency Analyser (PEA fluorometer; Hansatech Instruments) are less commonly employed, but have been used to address photo-physiological issues of both isolated zooxanthella (Iglesias-Prieto 1995) and zooxanthellae in hospite (Hill et al. 2004a). Both technologies utilise chlorophyll a fluorescence measurements and rely on the dark-adapted 'Kautsky' effect to induce fluorescence emission (e.g. Haldimann \& Strasser 1999, Hill et al. 2004a,b). Therefore, we expect that induction-curve analysis, along with fast-induction kinetics analysis, will identify photosynthetic responses of endosymbionts to anaerobic conditions.

This paper investigates the photosynthetic effect of air content and flow in the water surrounding corals, as well as identifying the most sensitive biomarker of anaerobic stress in corals. Using slow (PAM) and fast (PEA) induction kinetic techniques, we examine coral endosymbionts at a range of air saturation and flow conditions to investigate impacts of hypoxia on PSII of zooxanthellae in hospite.

\section{MATERIALS AND METHODS}

Pocillopora damicornis (Linnaeus) colonies were collected from Heron Island lagoon (<2 m deep) (152 $06^{\prime}$ E, $20^{\circ} 29^{\prime} \mathrm{S}$ ) over the period 26 January to 4 February 2003, and transported to the University of Technology, Sydney where they were allowed to acclimate for 2 mo in a 5001 aquarium supplied with recirculating artificial seawater (carbonate [140 ppm] and synthetic sea salt [Aquasonic 'Ocean Nature'] to $33 \mathrm{ppm}$ in reverseosmosis water, $26 \pm 1^{\circ} \mathrm{C}$ and $200 \mu \mathrm{mol}$ photons $\mathrm{m}^{-2} \mathrm{~s}^{-1}$ ). A nubbin was broken from $4 P$. damicornis colonies and held in the $500 \mathrm{l}$ aquarium to acclimatise for $14 \mathrm{~d}$ before experimentation. Induction-curve analysis (PAM) and fast-induction kinetics (PEA) were performed for each coral replicate $(\mathrm{n}=4)$.

Experimental protocol. One nubbin from each of the 4 colonies was transferred into a purpose-built darkacclimation chamber (2.8 $\mathrm{l}_{\text {; }}$ see Hill et al. 2004b) with continuously circulating $100 \%$ air-saturated seawater at $26 \pm 1^{\circ} \mathrm{C}$, at a flow rate of $4 \mathrm{~cm} \mathrm{~s}^{-1}\left(23 \mathrm{l} \mathrm{min}^{-1}\right.$ into an $11 \mathrm{~cm}$ diameter chamber). This was deemed to be an intermediate flow rate around a Pocillopora damicornis colony by Lesser et al. (1994). Each sample was acclimated for $10 \mathrm{~min}$ under $200 \mu \mathrm{mol}$ photons $\mathrm{m}^{-2} \mathrm{~s}^{-1}$ (LiCor) with actinic light provided by a halogen lamp $(12 \mathrm{~V}, 150 \mathrm{~W}$ with UV filter). A pilot study showed that 10 min of dark incubation was sufficient to fully darkadapt the samples. Water temperature was maintained using a temperature-regulated water bath (TH3 Thermoregulatory, Ratek Instruments) connected to the dark-acclimation chamber. Samples were dark-adapted for 10 min after which fast-induction-kinetic transients (PEA) were obtained. Actinic light of $200 \mu \mathrm{mol}$ photons $\mathrm{m}^{-2} \mathrm{~s}^{-1}$ was re-applied for a further $10 \mathrm{~min}$, after which the nubbin was dark-acclimated for $10 \mathrm{~min}$. Finally, induction-curve analysis (PAM) was performed. This procedure was repeated for the con- 
trol (100\% air-saturation with flow) and each of the 3 treatments: $40 \pm 5 \%$ air content with a flow regime of ca. $2 \mathrm{~cm} \mathrm{~s}^{-1}, 0$ to $2 \%$ air content with a flow regime of approximately $2 \mathrm{~cm} \mathrm{~s}^{-1}$, and $0 \%$ air content with no flow. Air saturation was regulated by adding $\mathrm{N}_{2}$ to the flow stream (Schreiber \& Vidaver 1974) and measured using oxygen-sensing $100 \mu \mathrm{m}$ optodes (Precision Sensing). It was assumed that $\mathrm{CO}_{2}$ was not limiting during $\mathrm{N}_{2}$ flushing, due to the volume of the chamber, the recirculation of water and the buffering capacity of bicarbonate in seawater. The optodes were calibrated linearly to $100 \%$ air saturation in $200 \mathrm{ml}$ of seawater, aerated with an air stone for at least $10 \mathrm{~min}$, and $0 \%$ air saturation in seawater, which had been flushed with $\mathrm{N}_{2}$ for at least $10 \mathrm{~min}$.

Slow (PAM) fluorescence measurements. Fluorescence measurements were performed using a DivingPAM - Walz settings: saturating intensity $(\mathrm{SI})=8$, saturating width $(\mathrm{SW})=0.8 \mathrm{~s}$, actinic intensity $(\mathrm{AI})=$ $3\left(=200 \mu \mathrm{mol}\right.$ photons $\left.\mathrm{m}^{-2} \mathrm{~s}^{-1}\right)$, actinic width $(\mathrm{AW})=$ $300 \mathrm{~s}$, absorption factor $(\mathrm{AF})=1$, gain $(\mathrm{G})=4$, damping (D) $=2$, induction delay (ID) $=40 \mathrm{~s}$, induction width $($ IW) $=20 \mathrm{~s}$. The Diving-PAM employs a $3 \mu$ s pulse from a red light-emitting diode (LED) with a peak emission at $650 \mathrm{~nm}$ as the measuring light $(0.15 \mu \mathrm{mol}$ photons $\mathrm{m}^{-2} \mathrm{~s}^{-1}$ ). Saturation pulses were of $>4500 \mu \mathrm{mol}$ photons $\mathrm{m}^{-2} \mathrm{~s}^{-1}$ and actinic light was of $100 \mu \mathrm{mol}$ photons $\mathrm{m}^{-2}$ $\mathrm{s}^{-1}$. Chlorophyll fluorescence was detected at wavelengths above $710 \mathrm{~nm}$.

Dark-light transition curves (induction curves) demonstrate the capacity of a tissue to regulate photosynthesis at a known level of irradiance. Tissue was dark-adapted initially for $10 \mathrm{~min}$, then actinic light of $200 \mu \mathrm{mol}$ photons $\mathrm{m}^{-2} \mathrm{~s}^{-1}$ was applied for $5 \mathrm{~min}$. In order to monitor the effective quantum yield ( $\left.\phi_{\text {PSII }}\right)$ and quenching parameters, a saturating pulse was applied every 20 s. $\phi_{\text {PSII }}$ and non-photochemical quenching (NPQ) were determined according to the following equations (Schreiber 2004):

$$
\begin{aligned}
\mathrm{NPQ} & =\left(F_{\mathrm{m}}-F_{\mathrm{m}}{ }^{\prime}\right) / F_{\mathrm{m}}{ }^{\prime} \\
\phi_{\mathrm{PSII}} & =\left(F_{\mathrm{m}}{ }^{\prime}-F_{\mathrm{t}}\right) / F_{\mathrm{m}}{ }^{\prime}
\end{aligned}
$$

where $F_{\mathrm{m}}$ is maximum dark-adapted fluorescence, $F_{\mathrm{m}}{ }^{\prime}$ is maximum light-adapted fluorescence and $F_{\mathrm{t}}$ is minimum light-adapted fluorescence. Maximum nonphotochemical quenching $\left(\mathrm{NPQ}_{\max }\right)$ was recorded 4 min into the induction curves of all treatments.

Fast (PEA) fluorescence measurements. The OJIP transient (nomenclature by Strasser et al. 1995) can be divided into 2 phases, the fast rise from the minimum fluorescence $\left(\mathrm{O} \approx F_{0}\right)$ to $\mathrm{J}$ and onwards to the intermediate step (I), and a slower rise to $F_{\mathrm{m}}(=\mathrm{P})$. The fluorescence rise from $\mathrm{O}$ to $\mathrm{J}$ corresponds to the reduction of the primary electron acceptor of PSII, $\mathrm{Q}_{\mathrm{A}}$, to $\mathrm{Q}_{\mathrm{A}}{ }^{-}$
(Strasser et al. 1995, Hill et al. 2004a). Fast-induction kinetics provide detailed information on the photochemical state of PSII, as well as the filling of the PQ pool (Govindjee 1995).

Fast-induction kinetics were measured using the Plant Efficiency Analyser (PEA) with coral samples after 10 min dark adaptation. The array of 6 red LEDs (peak wavelength $650 \mathrm{~nm}$ ) provided the saturating illumination (3200 $\mu$ mol photons $\mathrm{m}^{-2} \mathrm{~s}^{-1}$ ) and focused on an area $4 \mathrm{~mm}$ in diameter. A PIN-photodiode (shielded by a long-pass filter $>720 \mathrm{~nm}$ ) detected the fluorescence signal from the coral. The fluorescence signal was obtained over $2 \mathrm{~s}$ and recorded every $10 \mu \mathrm{s}$ for the first $2 \mathrm{~ms}$, every $1 \mathrm{~ms}$ for the first $1 \mathrm{~s}$ of sampling, and every $100 \mathrm{~ms}$ thereafter. The base fluorescence $\left(F_{0}\right)$ was measured at $0.05 \mathrm{~ms}(\mathrm{O})$, and $\mathrm{P}\left(F_{\mathrm{m}}\right)$ was recorded as the maximum fluorescence reached after a $1000 \mathrm{~ms}$ sampling period. Curves for each treatment were normalised to $F_{0}\left(F_{\mathrm{t}} / F_{0}\right)$ to illustrate the change in variable fluorescence $\left(F_{\mathrm{v}}\right)$. Furthermore, the relative variable fluorescence was calculated by double normalising to $\mathrm{O}$ and $\mathrm{P}\left(F_{\mathrm{t}}-F_{0}\right) /\left(F_{\mathrm{m}}-F_{0}\right)$ to illustrate the accumulation of the reduced form of $\mathrm{Q}_{\mathrm{A}}\left(\mathrm{Q}_{\mathrm{A}}^{-}\right)$ (Haldimann \& Strasser 1999). The efficiency of electron transport before $\mathrm{Q}_{\mathrm{A}}$ was calculated using the following formula (Lazár 1999):

$$
\varphi_{\mathrm{Po}}=1-\left(F_{0} / F_{\mathrm{m}}\right)
$$

where $F_{0}$ is minimum dark-adapted fluorescence and $F_{\mathrm{m}}$ is maximum dark-adapted fluorescence.

Statistical analyses. One-way analysis of variance (ANOVA, Glantz 2002) tests were used to determine if significant differences were present among the different air-content treatments in $F_{\mathrm{v}} / F_{\mathrm{m}}, \phi_{\mathrm{PSII}}$, and $\mathrm{NPQ}_{\max }$ (see Fig. 1), as well as 6 individual PEA parameters $(\mathrm{O}$, J, I, P, $F_{\mathrm{V}}$ and $\varphi_{\mathrm{Po}}$, see Table 1) and OJIP points (see Fig. 3A) along the curve. Where the assumptions of normality and equal variance failed ( $p<0.05)$, data was transformed using natural log. Transformed data successfully met the assumptions of normality and equal variance. Post-hoc comparisons were performed using the Holm test, which is less conservative than Tukey's HSD or Bonferroni and also controls the overall risk of a false-positive conclusion at the nominal level (Glantz 2002).

\section{RESULTS}

In a pilot study, the air content at the coral surface under $4 \mathrm{~cm} \mathrm{~s}^{-1}$ flow rates was monitored using optodes. Results showed that this was reduced from 100 to $35 \pm$ $5 \%$ air-saturation after $10 \mathrm{~min}$ in darkness. This was the lowest air content achievable (under flow) without $\mathrm{N}_{2}$ manipulation, thereby defining the $40 \%$ intermedi- 
ate air treatment. In a subset $(n=2)$ where the flow was re-established $(100 \%$ air $)$, the coral was able to completely reverse the impact of turning off the flow.

\section{Slow (PAM) fluorescence}

Maximum $\left(F_{\mathrm{v}} / F_{\mathrm{m}}\right)$ and effective $\left(\phi_{\mathrm{PSII}}\right)$ quantum yield, as well as $\mathrm{NPQ}_{\max }$ of the 4 different treatments, are shown in Fig. 1. $F_{\mathrm{v}} / F_{\mathrm{m}}$ was significantly reduced $(\mathrm{p}=$ 0.017 ) in the $0 \%$ air-saturation without flow treatment compared to the 100, 40 and $0 \%$ air-saturation treatments with flow. $\phi_{\text {PSII }}$ values for the severely airdepleted treatments $(0 \%$ air-saturation with and without flow) were significantly lower $(p<0.001)$ than those for the 100 and $40 \%$ air-saturation treatments. $\mathrm{NPQ}_{\max }$ was not significantly different $(\mathrm{p}=0.536)$ among all 4 treatments.

The induction curves for $\phi_{\text {PSII }}$ and NPQ showed similar shapes for the 100 and $40 \%$ air-saturation treatments, but differed for the air-depleted samples ( $0 \%$ air saturation with and without flow) (Fig. 2). The most conspicuous difference between these 2 groups was the fast down-regulation of $\phi_{\mathrm{PSII}}$ at the dark-light transition for the air-depleted samples (Fig. 2C,D), most likely due to a large rise in $F_{0}$ and a smaller decline in $F_{\mathrm{m}}$. NPQ declined after $100 \mathrm{~s}$ actinic light in the 100 and $40 \%$ air-saturation treatments, whereas it increased or remained steady in the $0 \%$ air-saturation treatments (with and without

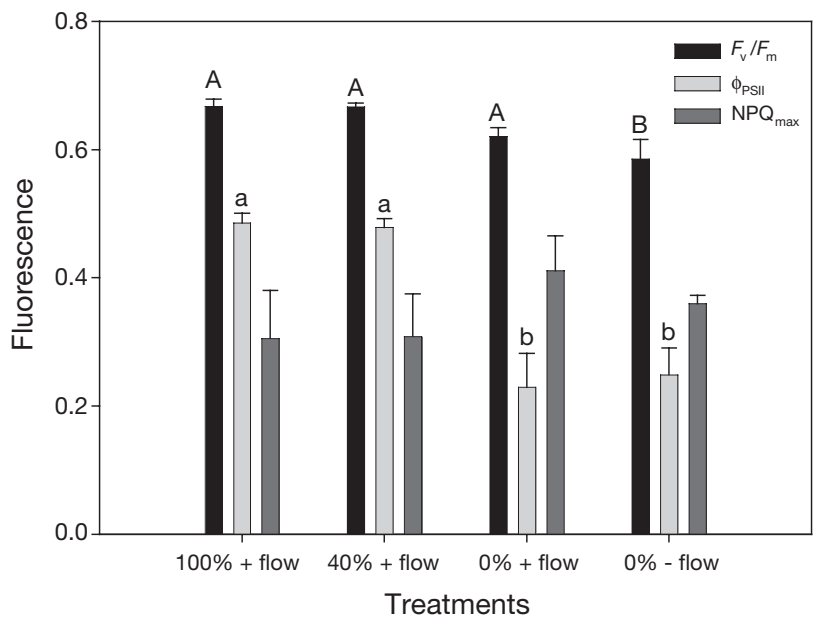

Fig. 1. Pocillopora damicornis. Effects of air-saturation and flow on maximum quantum yield, $F_{\mathrm{v}} / F_{\mathrm{m}}$, (black bars), effective quantum yield, $\phi_{\text {PSII }}$ (light grey bars) and maximum nonphotochemical quenching, $\mathrm{NPQ}_{\max }$ (dark grey bars) obtaining during induction curve analysis $(\mathrm{n}=4)$. The 4 treatments, $100 \%$ air-saturation, $40 \%$ air-saturation, $0 \%$ air-saturation with flow and $0 \%$ air-saturation without flow are shown including standard error bars. Values with different letters were found to be significantly different $(p<0.001)$ by the Holm test
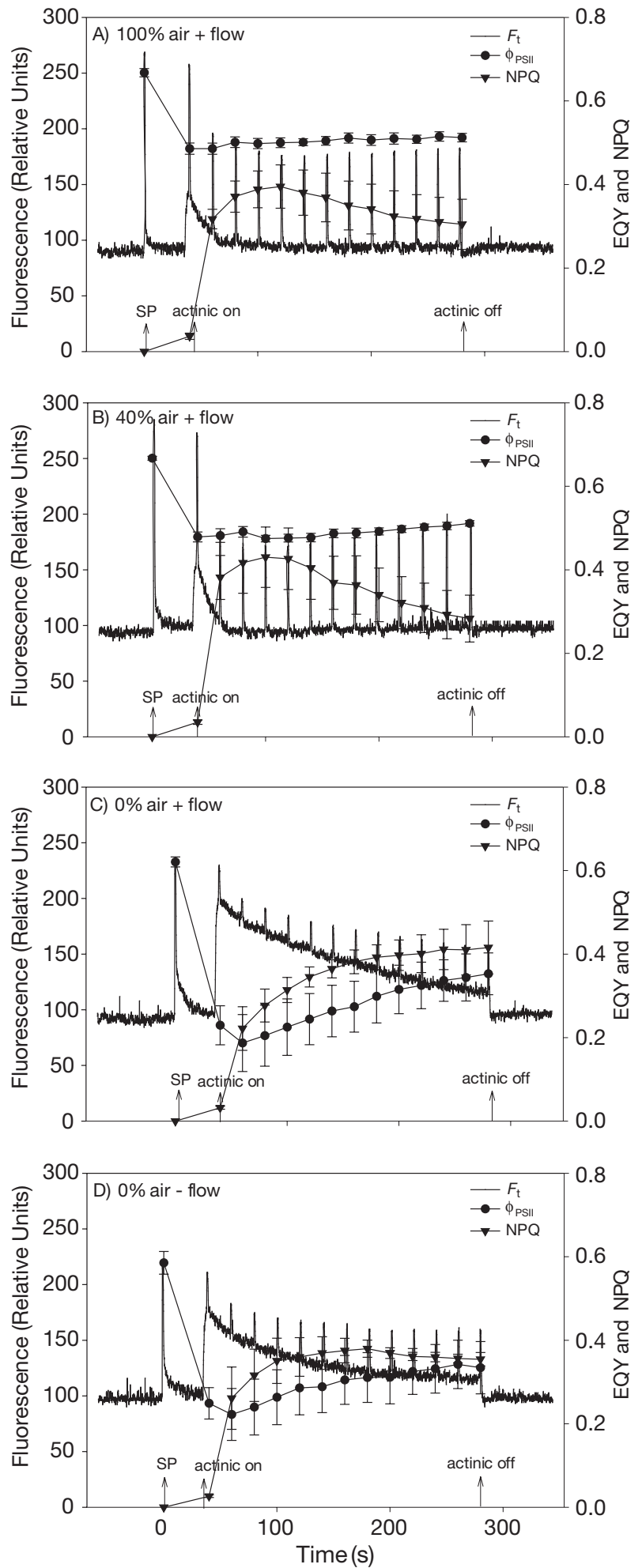

Fig. 2. Pocillopora damicornis. Induction-curve analysis of the 4 treatments, (A) $100 \%$ air-saturation, (B) $40 \%$ air-saturation, (C) $0 \%$ air-saturation with flow and (D) $0 \%$ air-saturation without flow. The curves represent mean values, including standard error bars $(\mathrm{n}=4)$ of $\phi_{\mathrm{PSII}}(\mathrm{EQY})$ and non-photochemical quenching (NPQ), and a representative curve showing $F_{\mathrm{t}}$ is superimposed on the data. SP: saturating pulse 
flow). Fig. 2 also shows a trace of $F_{\mathrm{t}}$ during the induction. Differences here were also dependent on air content, rather than flow. That is, there was no difference in curve shape between the 100 and $40 \%$ air-saturation treatments, in contrast to the $0 \%$ with and without flow treatments. The difference between the 2 groups was evident after the dark-light transition.

\section{Fast (PEA) fluorescence}

The fast-induction kinetics of the 4 treatments are shown in Fig. 3. When exposed to 100 and $40 \%$ air saturation, corals showed a classical OJIP curve (Fig. 3A) with no significant differences in the amplitudes of the peaks (Table 1). An analysis of the amplitudes of the O, J, I and P peaks allowed the detection of significant differences with the other 2 treatments (Table 1). The O peak was found to increase under anaerobic conditions ( $\mathrm{p}<0.001)$ and the Holm posthoc test revealed that there were also significant differences between the $0 \%$ air-saturation treatments, where the treatment with flow had a higher $O$ (Table 1). A significantly higher J peak amplitude was also observed in the $0 \%$ air-saturation with flow treatment, compared to the other 3 treatments ( $p<0.005)$. Following the $\mathrm{J}$ peak, the corals exposed to $0 \%$ air saturation with and without flow showed a pro- nounced dip, which was not apparent in the 100 and $40 \%$ treatments (Fig. 3A). The I and P peaks were greatly reduced $(\mathrm{p}<0.05)$ in the $0 \%$ air-saturation without flow treatment compared to the other treatments. Fig. 3B shows the fast-induction curves of the 4 treatments normalised to $F_{0}$. This presentation of the data (also see Table 2) allows a clearer understanding of the change in variable fluorescence $\left(F_{\mathrm{v}}=F_{\mathrm{m}}-F_{0} \approx\right.$ $\mathrm{P}-\mathrm{O}$ ) among the treatments, where the values for the $0 \%$ air-saturation with and without flow treatments were significantly lower than those for the 100 and $40 \%$ treatments. When double-normalised (Fig. 3C), the $\mathrm{J}$ peak was considerably higher in the $0 \%$ airsaturation with and without flow treatments than in the 100 and $40 \%$ treatments.

Variation in the time at which each peak occurred was also investigated. Table 1 shows that the timing of the $\mathrm{O}, \mathrm{J}$ and $\mathrm{P}$ peaks remained constant among treatments (0.05 ms, $2 \mathrm{~ms}$ and $1000 \mathrm{~ms}$, respectively), but the timing of the I peak varied. In the 100 and $40 \%$ airsaturation treatments, the I peak occurred at $50 \mathrm{~ms}, \mathrm{I}_{\mathrm{A}}$, whilst in the $0 \%$ with and without flow treatments, the I peak took longer to reach $(150 \mathrm{~ms}), \mathrm{I}_{\mathrm{B}}$.

An analysis of the electron transport efficiency before $\mathrm{Q}_{\mathrm{A}}\left(\varphi_{\mathrm{Po}}\right)$ also separated the treatments into the 2 groups of with air (100 and $40 \%)$ and without air $(0 \%$ with and without flow) (Table 2, p < 0.05). This shows that under conditions of $0 \%$ air, the electron transport efficiency before $\mathrm{Q}_{\mathrm{A}}$ had declined.

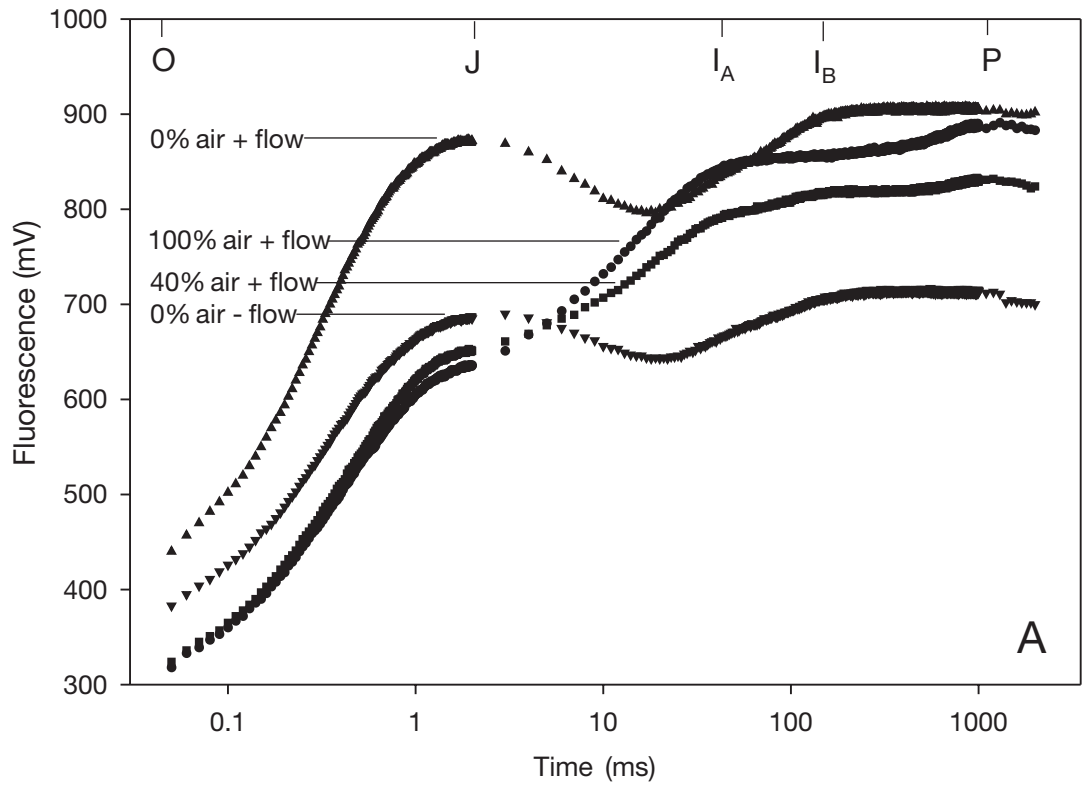

Fig. 3. Pocillopora damicornis. Fast-induction kinetic transient curves under $100 \%$ air-saturation $(\bullet), 40 \%$ air-saturation $(\boldsymbol{\square}), 0 \%$ air-saturation $(\boldsymbol{\Delta})$ and $0 \%$ air-saturation without flow $(\boldsymbol{\nabla})$. (A) Fluorescence transients, (B) transients normalised to $\mathrm{O}\left(F_{\mathrm{t}} / F_{0}\right)$, (C) relative variable fluorescence $\left(F_{\mathrm{t}}-F_{0}\right) /\left(F_{\mathrm{m}}-F_{0}\right)$ of the transients. Each transient represents the average of 1 treatment $(\mathrm{n}=4)$
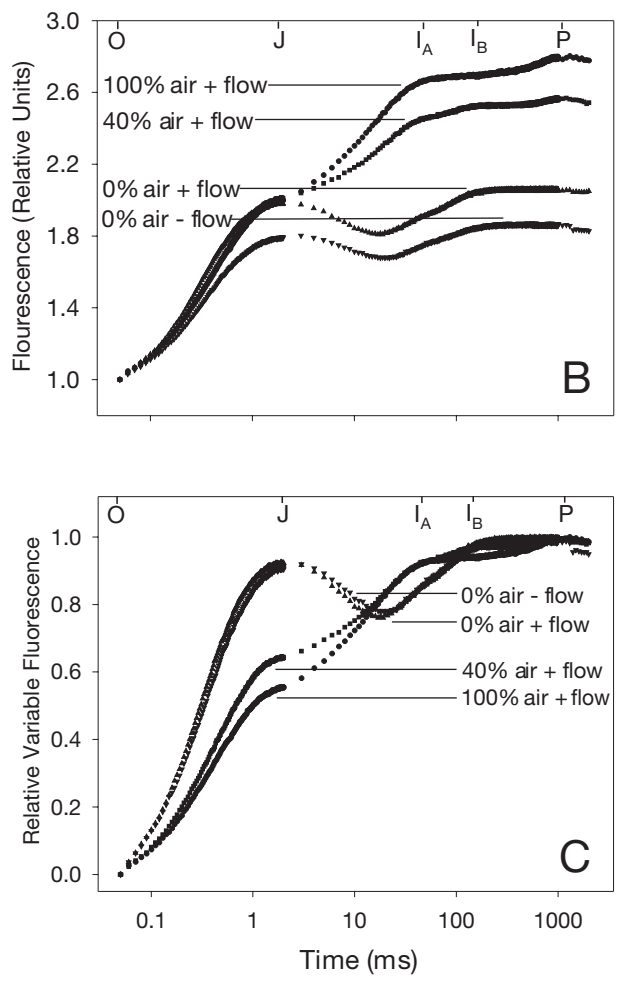
Table 1. Pocillopora damicornis. Amplitude and time of occurrence of the $\mathrm{O}, \mathrm{J}, \mathrm{I}$ and $\mathrm{P}$ peaks along the fast-induction curves for the 4 treatments, 100, 40 and $0 \%$ air-saturation with flow and $0 \%$ air-saturation without flow. Averages \pm SE of mean are shown $(n=4)$. Values with different superscript letters were found to be significantly $(p<0.05)$ different by the Holm test

\begin{tabular}{|c|c|c|c|c|c|c|c|c|}
\hline \multirow[b]{2}{*}{ Treatment } & \multicolumn{2}{|r|}{$\mathrm{O}$} & \multicolumn{2}{|r|}{$\mathrm{J}$} & \multicolumn{2}{|r|}{ I } & \multicolumn{2}{|r|}{$\mathrm{P}$} \\
\hline & $\begin{array}{l}\text { Time } \\
(\mathrm{ms})\end{array}$ & $\begin{array}{c}F \\
(\mathrm{mV})\end{array}$ & $\begin{array}{l}\text { Time } \\
(\mathrm{ms})\end{array}$ & $\begin{array}{c}F \\
(\mathrm{mV})\end{array}$ & $\begin{array}{l}\text { Time } \\
(\mathrm{ms})\end{array}$ & $\begin{array}{c}F \\
(\mathrm{mV})\end{array}$ & $\begin{array}{l}\text { Time } \\
(\mathrm{ms})\end{array}$ & $\begin{array}{c}F \\
(\mathrm{mV})\end{array}$ \\
\hline $100 \%+$ flow & 0.05 & $337.8 \pm 8.5^{\mathrm{a}}$ & 2 & $678.5 \pm 21.7^{\mathrm{a}}$ & 50 & $903.0 \pm 27.6^{\mathrm{a}}$ & 1000 & $946.3 \pm 25.5^{\mathrm{a}}$ \\
\hline $40 \%$ + flow & 0.05 & $355.5 \pm 15.9^{a}$ & 2 & $722.0 \pm 36.0^{\mathrm{a}}$ & 50 & $878.5 \pm 28.9^{\mathrm{a}}$ & 1000 & $914.3 \pm 28.0^{\mathrm{a}}$ \\
\hline $0 \%+$ flow & 0.05 & $458.7 \pm 5.5^{\mathrm{b}}$ & 2 & $909.0 \pm 13.4^{b}$ & 150 & $930.7 \pm 9.6^{\mathrm{a}}$ & 1000 & $937.0 \pm 7.7^{\mathrm{a}}$ \\
\hline $0 \%$ - flow & 0.05 & $410.8 \pm 1.9^{c}$ & 2 & $734.5 \pm 35.4^{\mathrm{a}}$ & 150 & $755.0 \pm 25.1^{b}$ & 1000 & $762.3 \pm 25.3^{b}$ \\
\hline
\end{tabular}

Table 2. Pocillopora damicornis. Fast-fluorescence transient parameters for the treatments 100, 40 and $0 \%$ air-saturation with flow and $0 \%$ air-saturation without flow. Averages $\pm \mathrm{SE}$ bars are shown $(\mathrm{n}=4)$. All parameters showed $\mathrm{p}$-values $<0.05$. Values with different superscript letters were found to be significantly $(p<0.05)$ different by the Holm test

\begin{tabular}{|c|c|c|c|c|}
\hline Parameter & $100 \%+$ flow & $40 \%+$ flow & $0 \%+$ flow & $0 \%-$ flow \\
\hline$F_{\mathrm{v}}$ & $608.5 \pm 19.7^{\mathrm{a}}$ & $558.8 \pm 15.5^{\mathrm{a}}$ & $478.3 \pm 10.9^{b}$ & $351.5 \pm 20.0^{\mathrm{b}}$ \\
\hline$\varphi_{\mathrm{Po}_{\mathrm{o}}}$ & $0.64 \pm 0.01^{\mathrm{a}}$ & $0.61 \pm 0.01^{\mathrm{a}}$ & $0.51 \pm 0.01^{\mathrm{b}}$ & $0.46 \pm 0.02^{b}$ \\
\hline
\end{tabular}

Anaerobiosis resulted in an increase in $F_{\mathrm{t}}$ after a saturating pulse in the dark (seen in Fig. 2C,D), and this fluorescence signal was slowly quenched when exposed to moderate actinic light (200 umol photons $\mathrm{m}^{-2} \mathrm{~s}^{-1}$ ). This is explained by the reduction of PSII reaction centres, which is linked to dark reduction of the PQ pool, a phenomenon known as chlororespiration (Harris \& Heber 1993). In light, fluorescence is

\section{DISCUSSION}

We set out to determine whether anaerobic conditions ultimately induce a decrease in the photosynthetic activity of zooxanthellae in hospite, whilst also identifying the most sensitive fluorescence biomarker of hypoxic conditions. Induction-curve analysis showed that $\phi_{\text {PSII }}$ decreased significantly $(p<0.01)$ after short periods of anoxic conditions (Fig. 1). This caused a reduction in the PQ pool, leading to increased PSII reaction centre closure. The rate at which dissipation of excess energy $\left(\mathrm{NPQ}_{\max }\right)$ occurred did not increase concurrently with a decline in $\phi_{\text {PSII }}$, which is often the case during bleaching events (Warner et al. 1996, Jones et al. 1998). However, the shape of the induction curves clearly indicates an increased rate of NPQ saturation in air-depleted treatments. This can also be inferred from the shape of the $F_{t}$ curves, in which the impact of low air-saturation $(0 \%)$ can be seen in the rate at which $F_{t}$ is quenched in the dark-light transition (Fig. 2C,D). This was also observed by Schreiber \& Vidaver (1975), who proposed that the recovery of photosynthesis, as manifested in $F_{\mathrm{t}}$, is dependent upon the dark-limiting steps of the re-oxidation of the PSII primary acceptor pool. The increase in $F_{\mathrm{t}}$ is thought to be linked to the watersplitting enzyme, hydrogenase, catalysing the endogenous electron reactions on the donor side of PSII, which is slowly induced during anaerobiosis (Schreiber \& Vidaver 1974). slowly quenched due to Photosystem I (PSI) gradually re-oxidising PSII (opening reaction centres) via the electron transport chain (Kaftan et al. 1999).

The fast-induction curves revealed several physiological changes, which occur in corals when exposed to anaerobic conditions (Fig. 3). For the 100 and $40 \%$ airsaturation treatments (Table 1), no significant differences were observed in the amplitudes of the O, J, I or $\mathrm{P}$ peaks, nor in the timing of each peak. This indicates that the various components of the photosynthetic apparatus are functioning similarly under these conditions. However, under conditions of $0 \%$ air-saturation with and without flow, changes in the fast-induction curves became apparent (Fig. 3). When the airsaturation was reduced to $0 \%$, a significant rise in the O peak was seen (Fig. 3A). This rise was maximal under $0 \%$ air-saturation with flow (Table 1). An increase in $F_{0}(O)$ has been suggested to occur as a result of the dissociation of the light-harvesting complex of PSII (LHC II) from the PSII reaction centres (Armond et al. 1978, Yamane et al. 2000). This response is common with high-temperature stress (Schreiber \& Berry 1977), although an alternative explanation for an increase in $F_{0}$ is the inhibition of electron flow from $Q_{A}$ to $Q_{B}$ (Bukhov et al. 1990, Yamane et al. 2000). This occurs in PSII reaction centres in darkness through the reduction of $\mathrm{Q}_{\mathrm{A}}$ by $\mathrm{PQ}$. The reduction of PQ may result from cyclic electron transport around PSI (Ravenel et al. 1994) or from chlororespiration (Garab et al. 1989). These 2 mechanisms result in the reduction of the elec- 
tron acceptors of PSII in the dark. Another possible contributor to a rise in $F_{0}$ is the decline in efficient energy trapping by PSII (Havaux 1993, Yamane et al. 2000).

A greater J peak amplitude occurred under the $0 \%$ air-saturation with flow treatment compared to the other 3 treatments, which all had similar J peak amplitudes (Fig. 3A). The $\mathrm{J}$ peak is indicative of the photochemical phase, where $\mathrm{Q}_{\mathrm{A}}$ is reduced to $\mathrm{Q}_{\mathrm{A}}{ }^{-}$under illumination (Govindjee 1995, Hill et al. 2004a). The increase in $\mathrm{J}$ indicates that there was a large increase in the rate of $\mathrm{Q}_{\mathrm{A}}$ reduction under $0 \%$ air-saturation with flow. This response is probably due to the accumulation of redox components in the electron transport chain, which become reduced in the dark (Haldimann $\&$ Strasser 1999). The probable mechanism responsible for this dark pre-reduction of the electron transport chain is chlororespiration or PSI cyclic electron transport (Yamane et al. 2000). An elevated J peak was only observed in the $0 \%$ air-saturation with flow treatment. The lack of a similar response in the $0 \%$ treatment without flow suggests that elevation of the J peak may not be a stable biomarker of anaerobiosis in zooxanthellae in hospite (Fig. 3A).

The $\mathrm{J}$ peaks in the $0 \%$ air-saturation with and without flow treatments were 97 and $96 \%$, respectively, of the maximum fluorescence ( $\mathrm{P}$ peak). In contrast, the same rise in the 100 and $40 \%$ air-saturation with flow treatments only contributed 72 and $79 \%$, respectively, of the maximum fluorescence. The transients of the airdepleted $(0 \%$ air-saturation with and without flow) treatments were thus dominated by the O-J rise, where $\mathrm{J}=\mathrm{I}=\mathrm{P}$ (Haldimann \& Strasser 1999). This indicates that the maximal fluorescence yield occurred at the J peak, due to the blockage of electrons beyond $\mathrm{Q}_{\mathrm{A}}$. The reduction in the efficiency of electron transport before $\mathrm{Q}_{\mathrm{A}}\left(\varphi_{\mathrm{Po}}\right)$ (Table 2 ) indicates that the dark reduction of the electron acceptors limits the capacity for $\mathrm{Q}_{\mathrm{A}}$ reduction. Also, the $\mathrm{P}$ peak was reduced in amplitude to the level of the J peak, due to the limited capacity for $\mathrm{Q}_{\mathrm{A}}$ re-oxidation. This provides further evidence that anaerobic conditions cause the reduction of the electron transport chain in the dark.

The anaerobic $(0 \%$ air-saturation with and without flow) treatments caused a significant dip to occur after the J peak (Fig. 3A). Schreiber \& Vidaver (1974) proposed that this dip occurs in response to enhanced PSI activity, which functions optimally under conditions of anaerobiosis. The dip after the $J$ peak in the fastinduction curves signifies that PSI cyclic electron transport is operating, possibly along with chlororespiration, causing the dark reduction of the electron acceptors and PQ pool (Schreiber \& Vidaver 1974). We speculate that this possible increase in PSI activity could also explain the delayed appearance of the I peak $\left(\mathrm{I}_{\mathrm{B}}\right)$ in the air-depleted treatments. In comparison, PSII becomes inhibited, which is demonstrated by the decline in $F_{\mathrm{v}} / F_{\mathrm{m}}$ (Fig. 1) and $F_{\mathrm{v}}$ (Table 2, Fig. 3B). Furthermore, I and $\mathrm{P}$ peak signals were lower in $0 \%$ air-saturation without flow compared to the other treatments, as a result of reduction of the PQ pool (Fig. 3A). The relative variable fluorescence (Fig. 3C) demonstrates that there is an elevation of the $\mathrm{J}$ peak with a decline in air saturation, due to the accumulation of $\mathrm{Q}_{\mathrm{A}}^{-}$under hypoxic conditions in the dark. From these fast-induction curves, the most sensitive biomarkers of the onset of anaerobiosis are a rise in $F_{0}$, a reduction in $\varphi_{\text {Po }}$ and an elevated $\mathrm{J}$ peak in double-normalised transients.

Future research is needed to demonstrate whether farred illumination is able to re-oxidise PQ and open the PSII reaction centres. Under far-red illumination, PSI activity would be stimulated, thus removing effects of dark-reduced electron acceptors in PSII under anaerobic conditions. Introducing $\mathrm{O}_{2}$ would also remove the anaerobiosis-dependent increase in fluorescence signal by oxidising the PQ pool (see Schreiber \& Vidaver 1974).

In conclusion, we have demonstrated that hypoxia indeed induces deviations from normal functioning PSII systems, through the measurements of both fast (PEA) and slow (PAM) chlorophyll a fluorescence. The 2 instruments were shown to complement each other in giving detailed information on the response of Pocillopora damicornis when exposed to decreased air and flow levels. Anaerobiosis can develop rapidly under low-flow conditions (Patterson et al. 1991, Kühl et al. 1995, Nakamura \& van Woesik 2001, Nakamura et al. 2003). This has important implications for coral bleaching events, which are intensified under such conditions. We observed similar photochemical impacts as those which occur during bleaching events (e.g. Jones et al. 1998, Hill et al. 2004b). Hypoxia and bleaching conditions in conjunction (i.e. doldrums, elevated temperature and high light) may intensify this response, which would suggest increased susceptibility of coral to bleaching. Furthermore, an important technical outcome of this research is that the use of dark-adapted coral samples held in low-volume facilities could lead to overestimation of the $F_{0}$ level (O peak, Table 1) and, thereby, distortion of other fluorescence parameters such as $\varphi_{\text {Po, }}, F_{\mathrm{v}}$ and $F_{\mathrm{v}} / F_{\mathrm{m}}$.

Acknowledgements. We thank N. Ralph for fabrication of the dark-adaptation chambers and Dr. F. Torpy and Dr. B. Kelaher for assistance in statistical analyses. Prof. A. W. D. Larkum contributed editorial comments. We are also thankful for the valuable comments of 3 anonymous reviewers. This work was performed with the permission of GBRMPA (permit number G03/9786.1). The Australian Research Council and the University of Technology, Sydney provided financial and logistical support. 


\section{LITERATURE CITED}

Armond PA, Schreiber U, Björkman O (1978) Photosynthetic acclimation to temperature in the desert shrub, Larrea divaricata. II. Light-harvesting efficiency and electron transport. Plant Physiol 61:411415

Brown BE, Downs CA, Dunne RP, Gibb SW (2002) Exploring the basis of thermotolerance in the reef coral Goniastrea aspera. Mar Ecol Prog Ser 242:119-129

Bukhov NG, Sabat SC, Mohanty P (1990) Analysis of chlorophyll a fluorescence changes in weak light in heat-treated Amaranthus chloroplasts. Photosynth Res 23:81-87

Dennison WC, Barnes DJ (1988) Effect of water motion on coral photosynthesis and calcification. J Exp Mar Biol Ecol 115:67-77

Garab G, Lajko F, Mustardy L, Marton L (1989) Respiratory control over photosynthetic electron transport in chloroplasts of higher plant cells: evidence of chlororespiration. Planta 179:349-358

Glantz SA (2002) Primer of biostatistics, 5th edn. McGrawHill, New York

Govindjee (1995) Sixty-three years since Kautsky: chlorophyll a fluorescence. Aust J Plant Physiol 22:131-160

Haldimann P, Strasser RJ (1999) Effects of anaerobiosis as probed by the polyphasic chlorophyll a fluorescence rise kinetic in pea (Pisum sativum L.). Photosynth Res 62: $67-83$

Harris GC, Heber U (1993) Effects of anaerobiosis on chlorophyll fluorescence yield in spinach (Spinacia oleracea) leaf discs. Plant Physiol 101:1169-1173

Havaux M (1993). Rapid photosynthetic adaptation to heat stress triggered in potato leaves by moderately elevated temperatures. Plant Cell Environ 16:461467

Hill R, Larkum AWD, Frankart C, Kühl M, Ralph PJ (2004a) Loss of functional Photosystem II reaction centres in zooxanthellae of coral exposed to bleaching conditions: using fluorescence rise kinetics. Photosynth Res 82:59-72

Hill R, Schreiber U, Gademann R, Larkum AWD, Kühl M, Ralph PJ (2004b) Spatial heterogeneity of photosynthesis and the effect of temperature-induced bleaching conditions in three species of coral. Mar Biol 144:633-640

Iglesias-Prieto R (1995) The effects of elevated temperature on the photosynthetic responses of symbiotic dinoflagellates. In: Mathis P (ed) Photosynthesis: from light to biosphere, Vol 4. Kluwer Academic Publishers, Dordrecht, p 793-796

Jones RJ, Hoegh-Guldberg O (2001) Diurnal changes in the photochemical efficiency of the symbiotic dinoflagellates (Dinophyceae) of corals: photoprotection, photoinactivation and the relationship to coral bleaching. Plant Cell Environ 24:89-99

Jones RJ, Hoegh-Guldberg O, Larkum AWD, Schreiber U (1998) Temperature-induced bleaching of corals begins with impairment of the $\mathrm{CO} 2$ mechanism in zooxanthellae. Plant Cell Environ 21:1219-1230

Jones RJ, Ward S, Amri AY, Hoegh-Guldberg O (2000) Changes in quantum efficiency of Photosystem II of symbiotic dinoflagellates of coral after heat stress, and of bleached corals sampled after the 1998 Great Barrier Reef mass bleaching event. Mar Freshw Res 51:63-71

Kaftan D, Meszaros T, Whitmarsh J, Nedbal L (1999) Characterization of Photosystem II activity and heterogeneity during the cell cycle of the green alga Scenedesmus quadricauda. Plant Physiol 120:433-441
Kirilovsky D, Etienne AL (1991) Protection of Reaction Center II from photodamage by low temperature and anaerobiosis in spinach chloroplasts. FEBS Lett 279:201-204

Kühl M, Cohen Y, Dalsgaard T, Barker JB, Revsbech NP (1995) Microenvironment and photosynthesis of zooxanthellae in scleractinian corals studies with microsensor for $\mathrm{O}_{2}$, pH and light. Mar Ecol Prog Ser 117:159-172

Lazár D (1999) Review: chlorophyll a fluorescence induction. Biochim Biophys Acta 1412:1-28

Lesser MP, Weis VM, Patterson MR, Jokiel PL (1994) Effects of morphology and water motion on carbon delivery and productivity in the reef coral, Pocillopora damicornis (Linnaeus): diffusion barriers, inorganic carbon limitation, and biochemical plasticity. J Exp Mar Biol Ecol 178:153-179

Miyake C, Ogawa K, Schreiber U, Asada K (1994) Donation of electron from NADPH to plastoquinone in thylakoids from higher plants. Plant Cell Physiol 35:s21

Nakamura T, van Woesik R (2001) Water-flow rates and passive diffusion partially explain differential survival of corals during the 1998 bleaching event. Mar Ecol Prog Ser 212:301-304

Nakamura T, Yamasaki H, van Woesik R (2003) Water flow facilitates recovery from bleaching in the coral Stylophora pistillata. Mar Ecol Prog Ser 256:287-291

Patterson MR, Sebens KP, Olson RR (1991) In situ measurements of flow effects on primary production and dark respiration in reef corals. Limnol Oceanogr 36:936-948

Ralph PJ, Gademann R, Larkum AWD (2001) Zooxanthellae expelled from bleached corals at $33^{\circ} \mathrm{C}$ are photosynthetically competent. Mar Ecol Prog Ser 220:163-168

Ravenel J, Peltier G, Havaux M (1994) The cyclic electron pathways around Photosystem I in Chlamydomonas reinhardii as determined in vivo by photoacoustic measurements of energy storage. Planta 193:251-259

Schreiber U (2004) Pulse-amplitude-modulation (PAM) fluorometry and saturation pulse method: an overview. In: Papageorgiou GC, Govindjee (eds) Chlorophyll fluorescence: a signature of photosynthesis. Kluwer Academic Publishers, Dordrecht, p 279-319

Schreiber U, Berry JA (1977) Heat-induced changes of chlorophyll fluorescence in intact leaves correlated with damage of photosynthetic apparatus. Planta 136:233-238

Schreiber U, Vidaver W (1974) Chlorophyll fluorescence induction in anaerobic Scenedesmus obliquus. Biochim Biophys Acta 368:97-112

Schreiber U, Vidaver W (1975) Analysis of anaerobic fluorescence decay in Scenedesmus obliquus. Biochim Biophys Acta 387:97-112

Schreiber U, Bird P, Ralph PJ, Larkum AWD, Kühl M (2002) Apparent light requirement for activation of photosynthesis upon rehydration of dessicated beachrock microbial mats. J Phycol 38:125-134

Strasser RJ, Srivastava A, Govindjee (1995) Polyphasic chlorophyll a fluorescence transient in plants and cyanobacteria. Photochem Photobiol 61:32-42

Warner ME, Fitt WK, Schmidt GW (1996) The effects of elevated temperature on the photosynthetic efficiency of zooxanthellae in hospite from four different species of reef coral: a novel approach. Plant Cell Environ 19: 291-299

Yamane Y, Shikanai T, Kashino Y, Koike H, Satoh K (2000) Reduction of $\mathrm{Q}_{\mathrm{A}}$ in the dark: another cause of fluorescence $\mathrm{F}_{0}$ increases by high temperatures in higher plants. Photosynth Res 63:23-34

Submitted: April 14, 2004; Accepted: September 30, 2004

Proofs received from author(s): January 5, 2005 